\title{
A new system for measuring electrical conductivity of water as a function of admittance
}

\author{
Haval Y. Yacoob Aldosky ${ }^{1}$ and Suzan M. H. Shamdeen ${ }^{2}$ \\ 1.Physics Dept. College of Science, University of Duhok,Duhok,Iraq,yacoobaldosky@uod.ac \\ 2. Physics Dept. College of Science, University of Zakho, Zakho, Iraq, suzan_zaxo@yahoo.com
}

\begin{abstract}
This paper presents a new system for measuring water conductivity as a function of electrophysical property (admittance). The system is cheap and its manufacturing is easy. In addition, it does not require any sort of electrolysis and calibration. The system consists of four electrodes made of silver (Ag $92.5 \mathrm{~g}$ to $\mathrm{Cu} 7.5 \mathrm{~g}$ ) fixed in a plastic tube filled by water which allows the use of two and four electrode setups. The admittance (reciprocal of impedance) was measured for different water sources (distilled, rainfall, mineral, river and tap water) using different frequencies between $50 \mathrm{~Hz}$ and $100 \mathrm{kHz}$. These measurements were taken twice, first with four electrodes and then with two electrodes of two modes (inner and outer electrodes). The results showed good correlation between the measured admittance and the conductivity of all the water sources and the best correlation was found at low frequencies between $50 \mathrm{~Hz}$ and $20 \mathrm{kHz}$. The highest efficiency can be achieved by using the four electrode system which allows circumventing the effect of the electrode impedance. This result makes the system efficient compared to traditional conductivity meters which usually require high frequencies for good operation.
\end{abstract}

Keywords: Impedance, Admittance, Water conductivity, four electrode setup

\section{Introduction}

The electrical conductivity (EC) of a water solution is a measure of how much material is dissolved in the water. EC is an important electrochemical water quality parameter. However, except for drinking water, EC alone is not adequate to characterize water. It has been suggested that drinking water quality can be checked effectively by measuring the conductivity of the water [1]. EC is usually measured by a probe that applies voltage between two electrodes and records the drop in voltage. This drop reflects the resistance of the water, which is then converted to conductivity. Electrical conductivity cannot be measured directly but it is calculated from the measurement of the resistance of an electrolyte where the conductivity and resistance are inversely related. According to [2] this relationship is given by

$$
R=\rho\left(\frac{l}{A}\right)=\left(\frac{1}{\kappa}\right)\left(\frac{l}{A}\right)=\frac{C}{\kappa}
$$

In equation (1) $R$ is the resistance, $\rho$ is the electrical resistivity, $k$ is the electrical conductivity with unit of Siemens/cm, $l$ is the effective length of the current path, $A$ is the effective cross-section area of the current path, and $C$ is the cell factor.

Although commercially available conductivity sensors are of good quality as far as range accuracy and sensitivity specifications are concerned they require extra cost [3]. Since all commercial conductivity meters incorporate temperature measurement an accurate electrical conductivity measurement is trivial even if the temperature and sometimes the water level are unknown. However, measuring the water level by a commercial conductivity meter is rather difficult [4]. Measuring EC conventionally requires calibration with a standard liquid and predetermination of the cell factor $\boldsymbol{C}$, which should be set to a constant, [4 and 5]. However, using a standard liquid and setting the cell factor to a constant value is not fully appreciated by most users because it is a costly process. The method of measuring water conductivity illustrated so far is based on electrochemical properties.

Conductivity can also be measured using electrophysical properties such as impedance $(Z)$ in units of (Ohm) and its reciprocal admittance (Y) in units of Siemens $\left(\mathrm{Ohm}^{-1}\right)$. Research concerning the use of admittance is infrequent. An exception is the work presented in [6] which used the concept of admittance for the first time to determine the conductivity of solid electrolytes.

In this paper a new system for measuring the conductivity of water is proposed. The system utilizes the correlation between the conductivity of water and the electrophysical parameters (impedance and admittance). It does not require calibration to a reference sample.

\section{The Proposed Setup}

There are two basic requirements (steps or procedure) for the conductivity measurement: 1) inducing a small ac current through a precise volume of the liquid to be studied and 2) measuring small changes of electric potential across the liquid. The first step is usually carried out by the conductivity measuring cell. The proposed setup consists of a function generator (Chauvin Arnoux C.A950), an RLC meter (M9803R), an ammeter (PeakTech 3340 DMM Auto 
range) and connecting wires. To fulfill the two aforementioned requirements the setup is designed to consist of two main components: cell fabrication and impedance measurement.

\section{Cell Fabrication}

The admittance cell is fabricated in a plastic tube of diameter $1.67 \mathrm{~cm}$ and length $9 \mathrm{~cm}$ with four silver electrodes ( $\mathrm{Ag} 92.5 \mathrm{~g}$ to $\mathrm{Cu} 7.5 \mathrm{~g}$ ) fixed inside the tube. The four silver electrodes each of diameter $1.67 \mathrm{~cm}$ and $0.6 \mathrm{~cm}$ thickness are arranged at equal distances of $1.5 \mathrm{~cm}$ apart as shown in figure (1).

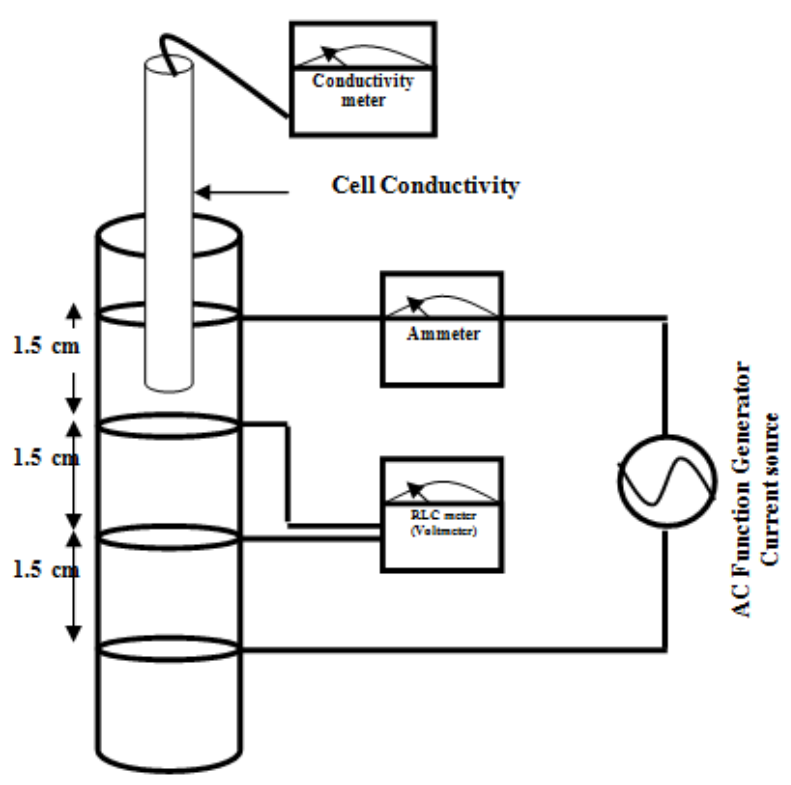

Figure (1) Fabricated cell with electrical circuit.

\section{Impedance and Admittance Measurement}

The impedance measurements are carried out at different frequencies ranging from $50 \mathrm{~Hz}$ to $100 \mathrm{kHz}$ by filling the tube with one water sample at a time (distilled, mineral, river, rainfall, and tap water). The voltage of the applied sinusoidal signal is about 10 volt rms. The electrical conductivity of the liquid is derived from its impedance $Z$. The admittance of the liquid is then calculated from the reciprocal of $Z$.

Two setups were considered; four electrodes and two electrodes with two modes.

In the four electrode setup, the impedance of the water samples is determined by the ratio of the electrical current (I) measured at the two outer electrodes and the measured potential drop $\Delta \mathrm{V}$ between the two inner electrodes.

In the two electrodes setup, one with two inner electrodes and the other with two outer electrodes, a voltage is applied to two electrode rings immersed in the water sample. Then the resultant current which is related to the small changes in the electric potential across the two electrodes is measured. The impedance is then determined in the same manner as mentioned above (the ratio between I and $\Delta \mathrm{V})$. The conductivity of water measured by both setups was compared to the measurements of a commercial conductivity $/{ }^{\circ} \mathrm{C}$ meter (Wagtech international) at room temperature $25^{\circ} \mathrm{C}$.

\section{Results and Discussion}

\section{Conductivity as a function of admittance}

The impedance and admittance measurements were performed at three different inter-electrode distances for each frequency. The design of the system allowed the use of both the four and two-electrode setup. These two setups and their results are illustrated in subsections A and B.

\section{A. Four Electrode Setup}

In the four electrode setup, a relationship between EC values measured by a commercial instrument EC meter and the admittance was established for different water samples at each frequency. Table (1) and Figure (2) show these relationships at frequencies $(0.05,2,20,60$ and $100 \mathrm{kHz})$. They can best be interpreted in accordance to the parameters of a linear equation (slope and intercept). The slope represents the distance between the electrodes. Figure (2) assures the correctness of the aforementioned interpretation. In this figure the slopes of the lines at low frequencies are $(1.7,1.66$ and 1.56) with correlation factor $\left(\mathrm{R}^{2}>0.99\right)$. These slope values approximate the distance between the electrodes $(1.5 \mathrm{~cm})$ with error percent $(9.3 \%)$. This result is in agreement with that of previous work [7].

In addition, the unit of the slope according to the figure is $\mathrm{cm}^{-1}$ which is the unit of the cell constant for any conductivity meter. So the distance between the electrodes can be taken as the cell constant of the four electrode setup. However, at high frequencies $(60,100 \mathrm{kHz})$ this interpretation is not feasible because the slopes of the lines exceeded the value of (2) with correlation factor $\left(\mathrm{R}^{2}<\right.$ $0.99)$. This value is rather far from $(1.5 \mathrm{~cm})$ the distance between the electrodes.

The other parameter of the linear equation is the intercept value. Ideally the intercept value should be zero. However, experimentally according to figure (2) the intercept values were $\left(3 \times 10^{-6}, 3 \times 10^{-6}\right.$, and $\left.6 \times 10^{-6}\right)$. These values can be considered as errors attributed to the electrode conductivity. This point was noticed previously in [2]. 
Table (1): Calculated values of admittance and measured conductivity for different frequencies by the 4-electrode system

\begin{tabular}{|c|c|c|c|c|c|c|c|c|c|c|}
\hline \multirow[b]{2}{*}{ 4-Electrodes } & \multicolumn{2}{|c|}{$f=0.05 \mathrm{kHz}$} & \multicolumn{2}{|c|}{$\mathrm{f}=2 \mathrm{kHz}$} & \multicolumn{2}{|c|}{$\mathbf{f}=20 \mathrm{kHz}$} & \multicolumn{2}{|c|}{$f=60 \mathrm{kHz}$} & \multicolumn{2}{|c|}{$f=100 \mathrm{kHz}$} \\
\hline & $\begin{array}{c}\text { Admittance } \\
(\mu \mathrm{S})\end{array}$ & $\begin{array}{c}\text { Conductivity } \\
(\mu \mathrm{S} / \mathrm{cm})\end{array}$ & $\begin{array}{c}\text { Admittance } \\
(\mu S)\end{array}$ & $\begin{array}{c}\text { Conductivity } \\
(\mu \mathrm{S} / \mathrm{cm})\end{array}$ & $\begin{array}{c}\text { Admittance } \\
(\mu S)\end{array}$ & $\begin{array}{c}\text { Conductivity } \\
(\mu \mathrm{S} / \mathrm{cm})\end{array}$ & $\begin{array}{c}\text { Admittance } \\
(\mu \mathrm{S})\end{array}$ & $\begin{array}{c}\text { Conductivity } \\
(\mu \mathrm{S} / \mathrm{cm})\end{array}$ & $\begin{array}{c}\text { Admittance } \\
(\mu \mathrm{S})\end{array}$ & $\begin{array}{c}\text { Conductivity } \\
(\mu \mathrm{S} / \mathrm{cm})\end{array}$ \\
\hline Distilled Water & 13.09 & 16.20 & 20.10 & 16.20 & 24.04 & 16.20 & 36.57 & 16.20 & 44.28 & 16.20 \\
\hline Mineral Water & 184.08 & 320.33 & 191.14 & 320.33 & 204.03 & 320.33 & 163.53 & 320.33 & 122.06 & 320.33 \\
\hline Rain fall Water & 37.84 & 79.56 & 39.75 & 79.56 & 45.23 & 79.56 & 48.85 & 79.56 & 53.69 & 79.56 \\
\hline River Water & 218.35 & 359 & 220.41 & 359 & 234.77 & 359 & 188.88 & 359 & 143.33 & 359 \\
\hline Tap Water & 243.70 & 429 & 258.40 & 429 & 282.73 & 429 & 235.10 & 429 & 171.61 & 429 \\
\hline
\end{tabular}

Conductivity vs Admittance @ frequencies 0.05,2,20,60,100 KHz for 4 electrodes

$$
\text { •f=0.05KHz } \quad \Delta \mathrm{f}=2 \mathrm{KHz} \quad * \mathrm{f}=20 \mathrm{KHz} \quad+\mathrm{f}=60 \mathrm{KHz} \quad-\mathrm{f}=100 \mathrm{KHz}
$$

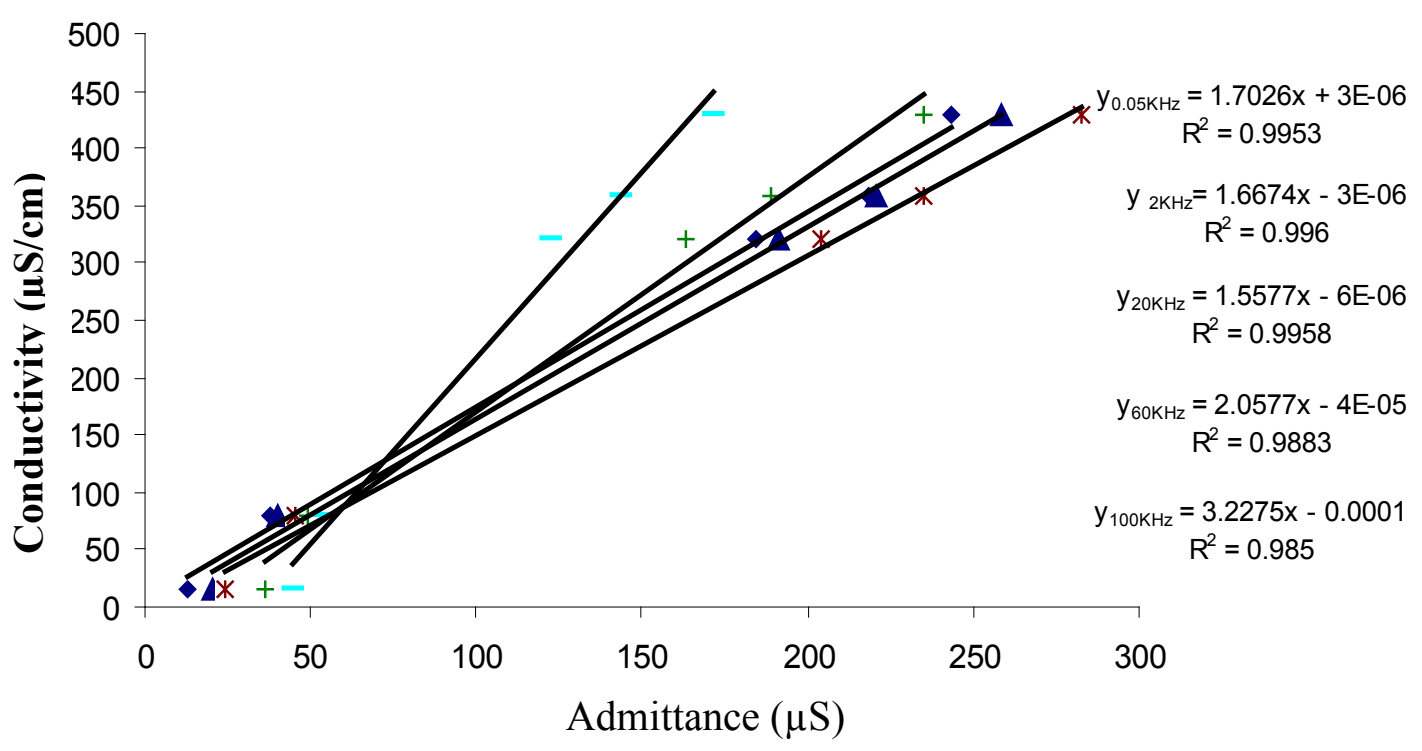

Figure (2): The relationship between admittance and conductivity is linear at frequencies $(0.05,2,20,60 \mathrm{and} 100 \mathrm{kHz})$ for the 4-electrode system.

\section{B. Two Electrode Setup}

In this setup two modes were considered; 2-inner and 2outer electrodes. Table (2) and figure (3) show the results for the 2-inner electrodes. According to the previous interpretation of the slopes and intercept values, the slope values were $(1.47,1.50$ and 1.57$)$ at low frequencies with correlation factor $\left(\mathrm{R}^{2} \approx 0.99\right)$. The average of these slope values was exactly equal to the distance between the electrodes $(1.5 \mathrm{~cm})$. Also at high frequencies $(60,100 \mathrm{kHz})$ this interpretation is not feasible because the slopes of the lines exceeded the value of (2) with correlation factor $\left(\mathrm{R}^{2}<\right.$ 0.99 ). According to figure (3) the intercept values were $\left(1 \times 10^{-5}, 1 \times 10^{-5}\right.$, and $\left.7 \times 10^{-6}\right)$.
Table (3) and figure (4) show the results for the 2-outer electrodes. The slope values of the lines were $(4.012,4.09$ and 4.567) at low frequencies with correlation factor $\left(\mathrm{R}^{2} \approx\right.$ $0.99)$. These slope values approximate the distance between the electrodes $(4.5 \mathrm{~cm})$ with error percent $(6.15 \%)$. However, at high frequencies $(60,100 \mathrm{kHz})$ the slopes of the lines were (5.759 and 7.93) with correlation factor $\left(\mathrm{R}^{2}<\right.$ $0.98)$. These values are rather far from $(4.5 \mathrm{~cm})$ the distance between the electrodes. The intercept values in figure (4) were small at low frequency and relatively large at high frequency. In general, it seems that the intercept values for the 4 electrodes setup were less than that of the two modes of two electrodes setups. This confirms the point that the effect of the electrode impedance in the four-electrode setup is smaller. 
Table (2): Calculated values of admittance and measured conductivity for different frequencies by the two-inner electrode system

\begin{tabular}{|c|c|c|c|c|c|c|c|c|c|c|}
\hline \multirow{2}{*}{$\begin{array}{c}\text { 2-Inner } \\
\text { Electrodes }\end{array}$} & \multicolumn{2}{|c|}{$f=0.05 \mathrm{kHz}$} & \multicolumn{2}{|c|}{$f=2 \mathrm{kHz}$} & \multicolumn{2}{|c|}{$f=20 \mathrm{kHz}$} & \multicolumn{2}{|c|}{$f=60 \mathrm{kHz}$} & \multicolumn{2}{|c|}{$\mathrm{f}=100 \mathrm{kHz}$} \\
\hline & $\begin{array}{c}\text { Admittance } \\
(\mu S)\end{array}$ & $\begin{array}{c}\text { Conductivity } \\
(\mu \mathrm{S} / \mathrm{cm})\end{array}$ & $\begin{array}{c}\text { Admittance } \\
(\mu S)\end{array}$ & $\begin{array}{c}\text { Conductivity } \\
(\mu \mathrm{S} / \mathrm{cm})\end{array}$ & $\begin{array}{c}\text { Admittance } \\
(\mu \mathrm{S})\end{array}$ & $\begin{array}{c}\text { Conductivity } \\
(\mu \mathrm{S} / \mathrm{cm})\end{array}$ & $\begin{array}{c}\text { Admittance } \\
(\mu \mathrm{S})\end{array}$ & $\begin{array}{c}\text { Conductivity } \\
(\mu \mathrm{S} / \mathrm{cm})\end{array}$ & $\begin{array}{c}\text { Admittance } \\
(\mu \mathrm{S})\end{array}$ & $\begin{array}{c}\text { Conductivity } \\
(\mu \mathrm{S} / \mathrm{cm})\end{array}$ \\
\hline Distilled Water & 2.91 & 16.20 & 3.77 & 16.20 & 10.38 & 16.20 & 20.25 & 16.20 & 23.81 & 16.20 \\
\hline Mineral Water & 216.85 & 320.33 & 208.53 & 320.33 & 201.52 & 320.33 & 184.76 & 320.33 & 155.85 & 320.33 \\
\hline Rain fall Water & 51.32 & 79.56 & 49.73 & 79.56 & 46.76 & 79.56 & 41.675 & 79.56 & 34.72 & 79.56 \\
\hline River Water & 215.94 & 359 & 212.23 & 359 & 204.36 & 359 & 187.76 & 359 & 158.41 & 359 \\
\hline Tap Water & 292.19 & 429 & 287.76 & 429 & 280.97 & 429 & 259.77 & 429 & 219.78 & 429 \\
\hline
\end{tabular}

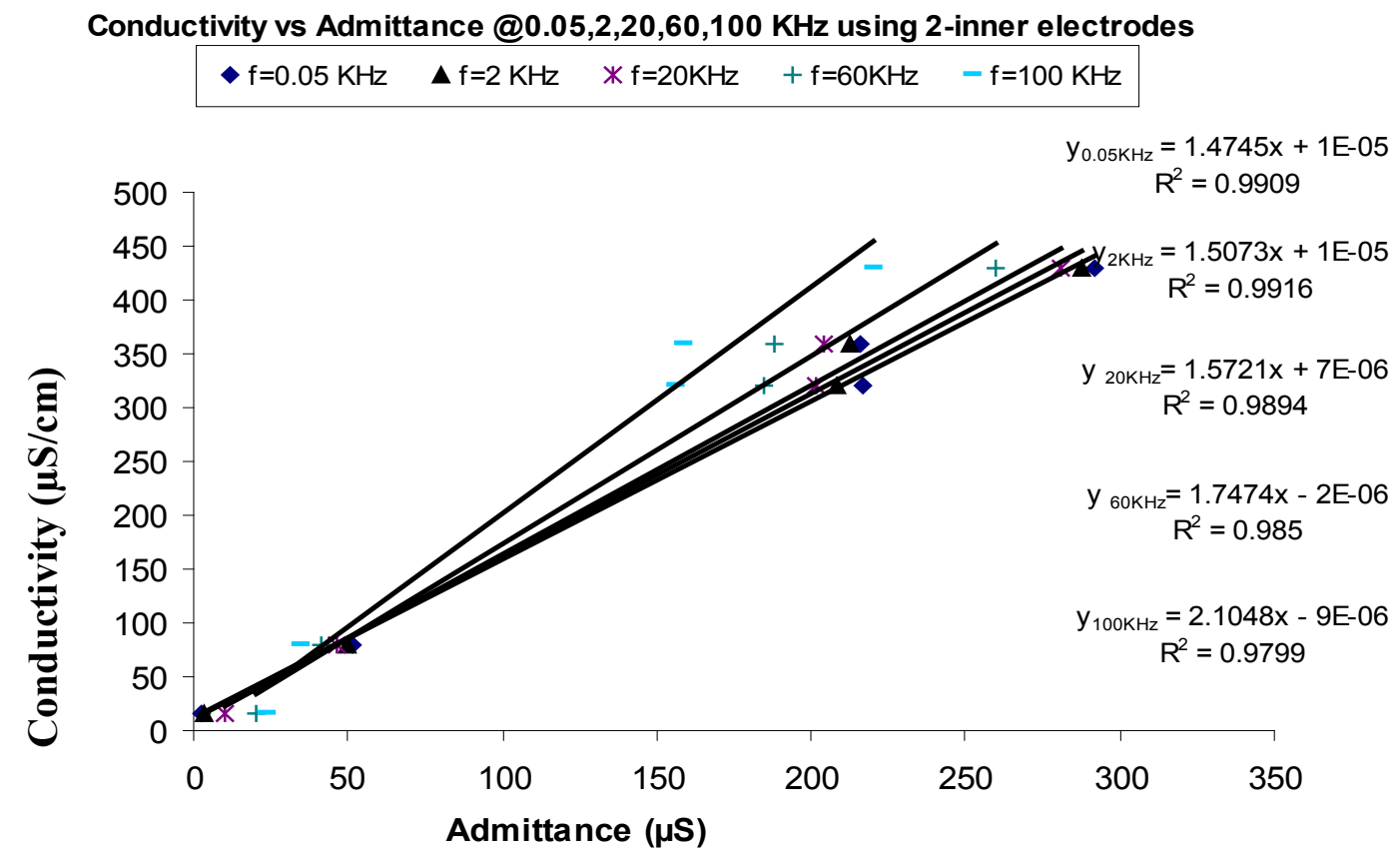

Figure (3): The linear relationship between admittance and conductivity at frequencies $(0.05,2,20,60$ and $100 \mathrm{kHz})$ for the 2-inner electrodes system.

Table (3) calculated values of admittance and measured conductivity for different frequencies by the 2-outer electrode system

\begin{tabular}{|c|c|c|c|c|c|c|c|c|c|c|}
\hline \multirow{2}{*}{$\begin{array}{l}\text { 2-Outer } \\
\text { Electrodes }\end{array}$} & \multicolumn{2}{|c|}{$f=0.05 \mathrm{kHz}$} & \multicolumn{2}{|c|}{$\mathrm{f}=2 \mathrm{kHz}$} & \multicolumn{2}{|c|}{$\mathrm{f}=20 \mathrm{kHz}$} & \multicolumn{2}{|c|}{$\mathrm{f}=60 \mathrm{kHz}$} & \multicolumn{2}{|c|}{$\mathrm{f}=100 \mathrm{kHz}$} \\
\hline & $\begin{array}{c}\text { Admittance } \\
(\mu \mathrm{S})\end{array}$ & $\begin{array}{c}\text { Conductivity } \\
(\mu \mathrm{S} / \mathrm{cm})\end{array}$ & $\begin{array}{c}\text { Admittance } \\
(\mu \mathrm{S})\end{array}$ & $\begin{array}{c}\text { Conductivity } \\
(\mu \mathrm{S} / \mathrm{cm})\end{array}$ & $\begin{array}{c}\text { Admittance } \\
(\mu \mathrm{S})\end{array}$ & $\begin{array}{c}\text { Conductivity } \\
(\mu \mathrm{S} / \mathrm{cm})\end{array}$ & $\begin{array}{c}\text { Admittance } \\
(\mu \mathrm{S})\end{array}$ & $\begin{array}{c}\text { Conductivity } \\
(\mu \mathrm{S} / \mathrm{cm})\end{array}$ & $\begin{array}{c}\text { Admittance } \\
(\mu \mathrm{S})\end{array}$ & $\begin{array}{c}\text { Conductivity } \\
(\mu \mathrm{S} / \mathrm{cm})\end{array}$ \\
\hline Distilled Water & 1.491 & 16.20 & 1.65 & 16.20 & 6.62 & 16.20 & 15.78 & 16.20 & 20.05 & 16.20 \\
\hline Mineral Water & 77.15 & 320.33 & 75.05 & 320.33 & 72.13 & 320.33 & 63.44 & 320.33 & 51.98 & 320.33 \\
\hline Rain fall Water & 18.33 & 79.56 & 18.40 & 79.56 & 19.44 & 79.56 & 22.51 & 79.56 & 23.60 & 79.56 \\
\hline River Water & 79.03 & 359 & 77.42 & 359 & 73.69 & 359 & 65.26 & 359 & 53.55 & 359 \\
\hline Tap Water & 108.60 & 429 & 107.20 & 429 & 100 & 429 & 89.52 & 429 & 73.56 & 429 \\
\hline
\end{tabular}




\section{Conductivity vs Admittance @ 0.05,2,20,60,100 KHz using 2-outer electrodes}

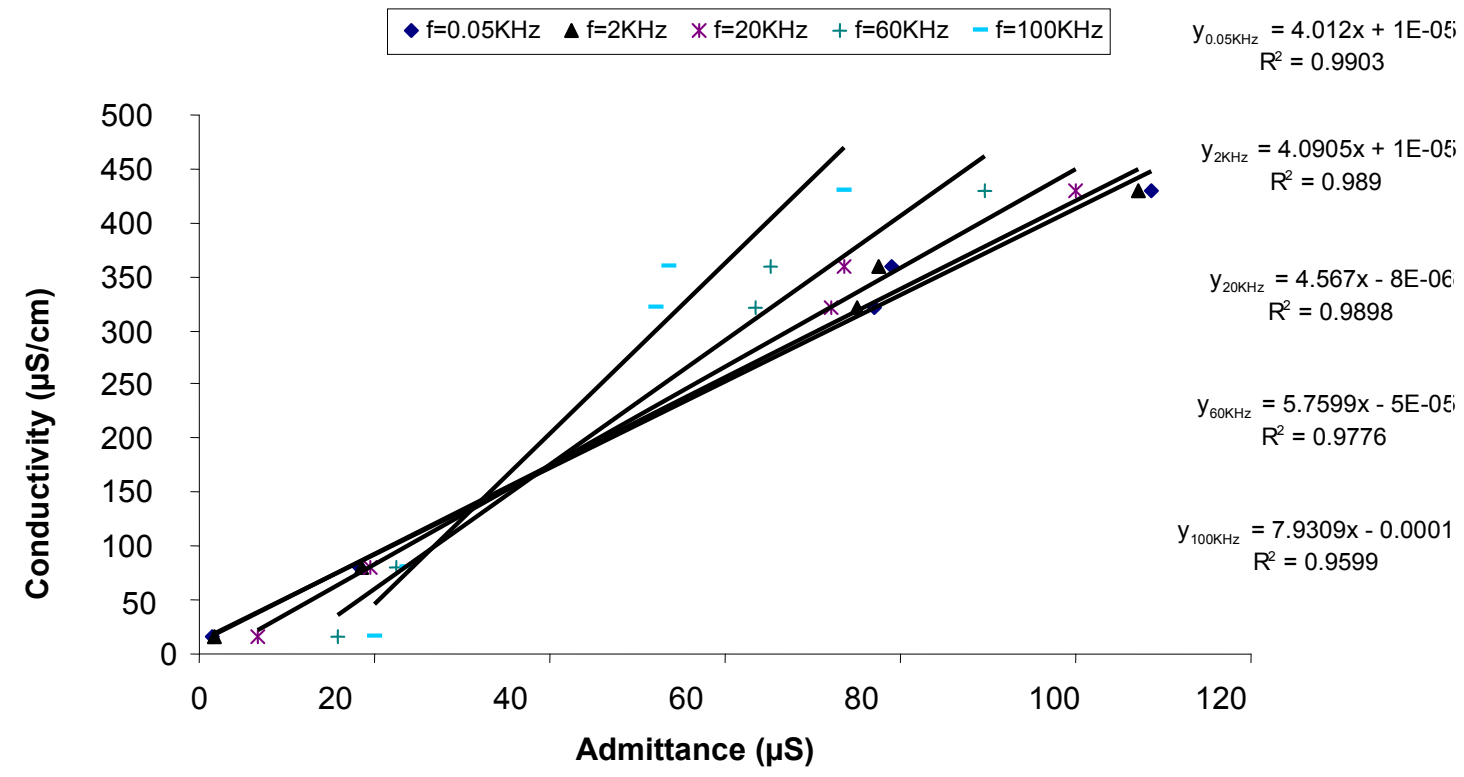

Figure (4): The linear relationship between admittance and conductivity at frequencies $(0.05,2,20,60$ and $100 \mathrm{kHz})$ for the 2-outer electrode system.

\section{The Influence of electrodes setup}

The influence of the three electrode setups (four, 2-inner and 2-outer) on the admittance measurements of the water samples was studied. Table (4) and figure (5) illustrates that the admittance of the water samples especially at low frequencies is changed depending on the electrode setup. This figure clearly shows that the admittance in the four

Table (4): Comparing the values of impedance and admittance for the three experimental setups (4, 2-inner, and 2 -outer electrodes) at all frequencies of distilled water.

\begin{tabular}{|c|c|c|c|}
\hline \multicolumn{4}{|c|}{ Distilled Water } \\
\hline f / kHz & $\begin{array}{c}\text { Admittance }(\mu \mathrm{S}) \\
2 \text {-Outer } \\
\text { Electrodes }\end{array}$ & $\begin{array}{c}\text { Admittance }(\mu \mathrm{S}) \\
\text { 2-Inner } \\
\text { Electrodes }\end{array}$ & $\begin{array}{c}\text { Admittance }(\mu \mathrm{S}) \\
\text { 4-Electrodes }\end{array}$ \\
\hline 0.05 & 1.49 & 2.91 & 13.09 \\
\hline 2 & 1.65 & 3.77 & 20.10 \\
\hline 6 & 2.55 & 5.06 & 24.96 \\
\hline 20 & 6.62 & 10.38 & 24.03 \\
\hline 60 & 15.78 & 20.25 & 34.16 \\
\hline 100 & 20.05 & 23.81 & 44.28 \\
\hline
\end{tabular}

electrode setup is greater than those of the two electrode setups at the same frequency. This can be attributed to the fact that increasing the number of electrodes makes the area of charge accumulation around each electrode smaller. This means that the charge transfer resistance decreases, which in turns leads to an increase in the admittance. These results agree with those reported in [8,9 and 10].

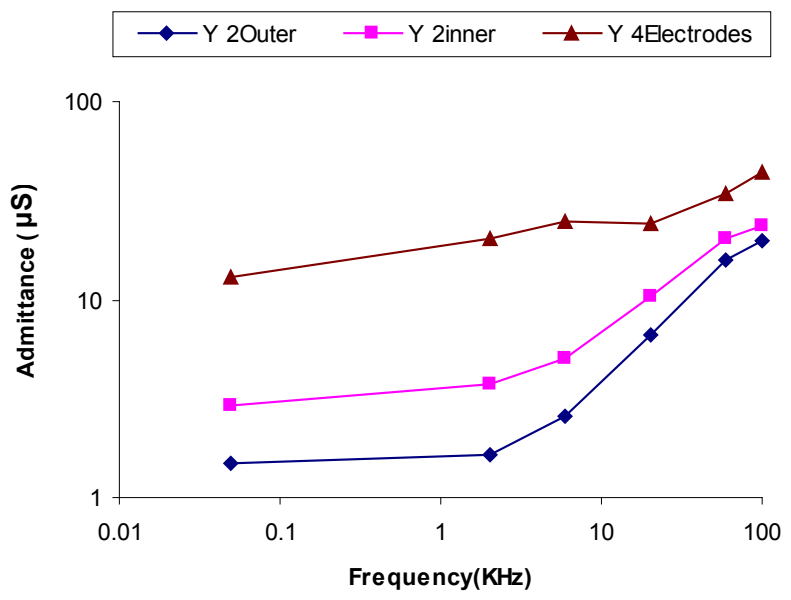

Figure (5): Admittance vs. frequency for the three experimental setups (4, 2-inner, and 2-outer electrodes) with the distilled water. 
Table (5) the influence of the three experimental setups (2-Inner, 2-Outer and 4- Electrodes) on the impedance and admittance values.

\begin{tabular}{|c|c|c|c|c|c|c|}
\hline \multicolumn{7}{|c|}{ Distilled Water } \\
\hline $\begin{array}{l}\text { Frequency } \\
(\mathrm{kHz})\end{array}$ & $\begin{array}{c}\text { Impedance }(\mathrm{k} \Omega) \\
\text { 2-Inner electrodes }\end{array}$ & $\begin{array}{c}\text { Impedance }(\mathrm{k} \Omega) \\
\text { 2-Outer electrodes }\end{array}$ & $\begin{array}{c}\text { Impedance }(\mathrm{k} \Omega) \\
\text { 4-electrodes }\end{array}$ & $\begin{array}{c}\text { Admittance }(\mu \mathrm{S}) \\
\text { 2-Inner electrodes }\end{array}$ & $\begin{array}{c}\text { Admittance }(\mu \mathrm{S}) \\
\text { 2-Outer electrodes }\end{array}$ & $\begin{array}{c}\text { Admittance }(\mu \mathrm{S}) \\
\text { 4-electrodes }\end{array}$ \\
\hline 0.05 & 343.23 & 670.80 & 76.40 & 2.91 & 1.49 & 13.08 \\
\hline 2 & 265.16 & 606.41 & 49.74 & 3.77 & 1.64 & 20.10 \\
\hline 6 & 197.72 & 392.62 & 39.79 & 5.05 & 2.54 & 25.13 \\
\hline 20 & 96.33 & 151.11 & 41.60 & 10.38 & 6.61 & 24.03 \\
\hline 60 & 49.36 & 63.37 & 29.26 & 20.25 & 15.78 & 34.17 \\
\hline 100 & 42.00 & 49.87 & 22.58 & 23.80 & 20.05 & 44.28 \\
\hline
\end{tabular}

The configuration of the electrodes also contributes to the increase in the measured admittance. For the four electrode setup there is no current flow through the voltage measurement electrodes, thus there is no voltage drop across these electrodes. This is illustrated by table (5).

In contrast, for the two electrode setup with two modes (inner and outer), the measured impedance was greater than that of the four electrode setup as shown in table (5). This table shows that the impedance of the two electrode setup is high because the voltage measurement electrode is the same as the current supply electrode thus the voltage that appears between them is affected by the voltage drop caused by the impedance of the electrodes. This result has been reported in [11].

The influence of the distance between the electrodes on the measured impedance can be explained as follows: the larger the distance between the electrodes the larger is the reactance capacitance value of the water sample. This behavior is especially feasible for the 2-outer mode of the two electrode setup. This makes the impedance to be higher, as seen in table (5). The same explanation was given in [12]. Table (5) shows that the four electrode setup is efficient for minimizing the impedance values. Thus the problem of electrode polarization can largely be eliminated for the four electrode setup.

Although the electrode polarization exists in the two electrode setup, it can still be used as an alternative setup as the results it gave were fair and acceptable as shown in figures ( 3 and 4). The acceptance of the two electrode setup may be due to the large surface areas of the electrodes which lead to a reduction in the electrode impedance.

\section{Conclusion}

In the view of the aforementioned results, the admittance measured by the three different electrode setups correlates well with the conductivity of water. Best results can be achieved by performing the four electrode setup which allows more flexibility in controlling the effect of the electrode impedance. It can be concluded that the proposed setups are suitable for measuring the conductivity of water samples within a wide range (including very low conductivity of distilled water to high conductivity of tap water).

Finally, the development of the setup was simple and cheap. It did not cost more than a plastic tube and four silver rings.

\section{Acknowledgment}

The authors would like to thank the Physics and Chemistry Departments, Faculty of Science, University of Zakho, Kurdistan Region, Iraq, for their support.

\section{References}

1. Navneet Kumar and D.K. Sinha, Drinking water quality management through correlation studies among various physicochemical parameters: A case study. Intern. J. Environ. Sci. 2010; 1, 2.

2. Susan L. Schiefelbein, Naomi A. Fried, Kevin G. Rhoads, and Donald R. Sadoway, A high-accuracy, calibration-free technique for measuring the electrical conductivity of liquids. Review Sci. Instr. 1998; 69, 9.

3. David H.P. Liu and Bda G. Liptik, ed. (2 ${ }^{\text {nd }}$ Ed.). Environmental Engineers' Handbook. CRC Press LLC. Rocs Raton. Flonda. 1997; p. 575.

4. Torrents M. Josep, Low-cost Conductivity Cells for Water Measurement Purposes. Instrumentation and Measurement Technology Conference, Coma Italy. 2004;18-20 May

5. Jikun Yia, Wei Lia,, Lingfang Wanga, and Zhiyu Wen, The Simulation of Frequency-Capacitance characteristics of Fresh Water Conductivity Sensor. Proceedings of the 2009 4th IEEE International Conference on Nano/Micro Engineered and Molecular Systems January 5-8, 2009, Shenzhen, China. 
6. Krishnan C.V., M. Garnett, and B. Chu, Solute-Solvent Interactions in Biological Molecules: L-Cysteine. Int. J. Electrochem. Sci., 2008; 3, 854 - 872.

7. Pop G.A., T.L. de Backer, M. de Jong, P.C. Struijk, L. Moraru, Z. Chang, H.G. Goovaerts, C.J. Slager, and A.J. Bogers, On-Line Electrical Impedance Measurement for Monitoring Blood Viscosity during On-Pump Heart Surgery. Eur. Surg. Res. 2004; 36, 259-265. http://dx.doi.org/10.1159/000079910

8. Frederic Laugere, Rosanne M. Guijt, Jeroen Bastemeijer, Gert van der Steen, Axel Berthold, Erik Baltussen, Pascalina Sarro, Gijs W. K. van Dedem, Michiel Vellekoop, and Andre Bossche, On-Chip Contactless Four-Electrode Conductivity Detection for Capillary Electrophoresis Devices. Anal. Chem. 2003; 75, 306-312. http://dx.doi.org/10.1021/ac0157371
9. Jinsong $\mathrm{Yu}$ and Chung-Chiun Liu, Microfabricated Thin Film Impedance Sensor \& AC Impedance Measurements. Sensors, 2010; 10, 5845-5858. http://dx.doi.org/10.3390/s100605847

10. Riaz Ahmed and Ken Reifsnider, Study of Influence of Electrode Geometry on Impedance Spectroscopy. Int. J. Electrochem. Sci., 2011; 6, 1159 - 1174.

11. Sonia Pérez-Vázquez Losada, Implementation of an Electrical Bioimpedance Measurement System for Renal Function Monitoring. Final Degree Thesis 30 ECTS, Erasmus 2007-08, University College of Borås, Sweden, School of Engineering, 2008.

12. Behzadi G. and H. Golnabi, Investigation of Conductivity Effects on Capacitance Measurements of Water Liquids Using Cylindrical Capacitive Sensor. J. Appl. Sci., 2010; 10(4), 261-268. http://dx.doi.org/10.3923/jas.2010.261.268 